\title{
Introduction, Courtship, Wedding, and Family
}

\author{
Marvin L. Birnbaum, MD, PhD
}

A major milestone for out-of-hospital emergency medical care was reached during the Summer Scientific Assembly of the National Association of Emergency Medical Services Physicians (NAEMSP) in Portland, Oregon, USA, on 13 August 1994. It consisted of very real efforts on the part of the administrators, nurses, paramedics, and physicians to come together with the manufacturers who supply the equipment required for out-of-hospital emergency medical care. A forum was provided for the expression of perceptions, exchange of ideas, and the gathering of information; one entire day was devoted toward gaining an understanding of each other's perspectives, problems, and directions.

The interest of emergency medical services (EMS) physicians in pursuing an enhanced relationship with the equipment/device manufacturers in the United States first occurred at a palpable level during the EMS Today Conference of 1991 in Tucson, Arizona. An open forum between EMS and disaster management physicians and the manufacturers and their respective vendors was provided during that event. For many, the event constituted the first real handshaking introduction between these major components of the EMS system.

Following this introduction, several efforts attempted to integrate those who provide the clinical care with those who conceive, design, research, develop, and, ultimately market the products upon which competent clinical practice depends. However hesitant, this courtship by the EMS physicians continued. Further shoves were promulgated by the straight-forward message from Steve Schmidt of Ferno, Inc. published in Volume 8 of Prehospital and Disaster Medicine (PDM) and by a major confrontation between the medical device manufacturers and a federal regulatory agency that nearly capsized some of the major players in the industry. The letter to the editor of PDM from Schmidt chastised EMS physicians and other organizations associated with the delivery of EMS for not including the manufacturers as full participants in EMS decisions. The regulatory issues surfaced as restraining actions associated with the production of some of the devices essential to clinical practice. All of these factors combined to prompt the "day of understanding" on the 13th of August.

Persons involved in every aspect of the EMS industry participated. The regulatory agency involved, though not represented directly, was represented by the chair of the discussions. Each of the participants expressed their respective perceptions of the other, and each side learned a great deal. Major changes in perceptions resulted.

What really happened was the discovery that we have a common underlying goal: To provide the best care possible to persons whose lives are in need of help. Although it is possible to charge that the manufacturers are in the out-of-hospital EMS industry purely for financial profit, it became clear that the manufacturers care far beyond this pecuniary reward (for which they take great risks), in that they care that their products meet the clinicians', and hence the patients', needs. The manufacturers will generate financial profits (revenue beyond their research and development costs) only if the products are helpful in meeting the needs of the clinician in caring for the patients. We depend mutually on one another.

I thought that I was quite knowledgeable about the device manufacturing industry, but I learned an immense amount, developed a greater understanding of the process required to bring an idea from conception through to market, and now recognize I knew little. I suspect that most of those in attendance experi- 
enced a similar reaction to the events. Not only did chief executive officers and managers interact with the group, but exercises were conducted in product evaluation, think-tank ideas were generated and exchanged, and penetrating questions were asked and answered; and we all are the better for it.

However, it worked both ways. The manufacturers recognized a sincere desire of the providers of out-ofhospital emergency medical care to participate in the development of products as early in the product evolution process as is possible. This should begin in the need identification phase of development and continue throughout the process. There was substantial support for this notion provided during this meeting, and for this, I applaud the membership of NAEMSP in attendance. I urge the manufacturers to accept the gauntlet offered by the providers and to integrate the providers further into the process of moving a product from conception to actualization. The cost-savings to all involved from such a relationship may be great. We must move down this road together.

Another major impetus for this exchange was the recent experiences by all of us comprising the EMS industry in the United States with the actions of a federal regulatory body. Regardless of the motivation of this agency, its actions affected each of our clinical prac- tices, and, hence, those persons for whom we provide care. Perhaps the regulation of this part of our practice is perceived by some as poor, and few, if any, will argue with the need to "protect the public." But, regulation has as its responsibility not only "the protection of the public," but also has a duty to facilitate the long and laborious development process. The necessary result must be moving needed products and supplies from the brainstorming sessions into the hands of the providers with the greatest dispatch possible. This is necessary to optimize the care delivered on the streets. Delays can be as deleterious to patient care as is poor safety. Indeed, the agency has attempted to reinitiate the cooperative mode it previously held. We should accept the gauntlet and work to help the agency find better ways to define and achieve its goals, and these actions will facilitate attaining our objectives as well. Nothing will be gained by dwelling on perceived past indiscretions, but together we must begin again. We now have a better understanding of each of the components and their respective motivation. We must wed.

All the elements of this process, providers, manufacturers, and regulators must work together to optimize patient care. We all do the best that we can and are traveling down the same road. Together, we are a family. We must participate in the wedding. 


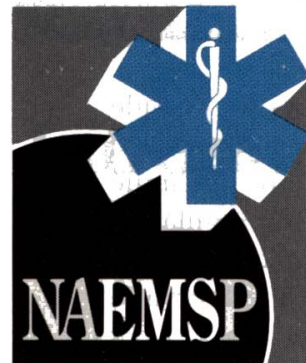

The National Association of EMS Physicians fosters excellence and provides medical leadership with the goal that all individuals and communities receive high quality out-of-hospital emergency medical care.

\section{Membership Information}

Full -- Full members shall be physicians who have a vital interestin the planning, supervision, teaching or clinical practice of out-of-hospital emergency medical care. \$195/year

Professional -- Professional members shall be those persons who have demonstrated an interest in out-of-hospital emergency medical care and the aims of the Association. \$75/year

\section{Fellow/Resident Physician/}

Medical Student -- Fellow/Resident Physician/Medical Student members shall be resident physicians or medical students interested in out-of-hospital emergency medical care. \$75/year

For a membership application form write to:

National Association of EMS Physicians 230 McKee Place, Suite 500

Pittsburgh, PA 15213

\section{1-800-228-3677}

*All memberships include journal subscription, discount meeting rates, newsletter and access to the EMS database.

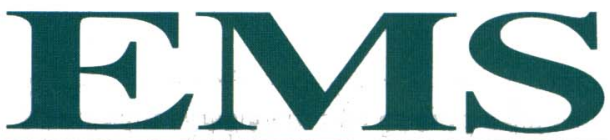

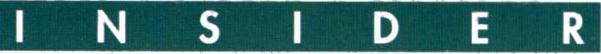

\begin{tabular}{lllll} 
THE NEWSLETTER FOR EMS MANAGERS \\
\hline
\end{tabular}

\section{Where the real news is reported-first.}

The EMS INSIDER is the finest source of concentrated EMS news available today. Published by Jems Communications and backed by an insistence on quality reporting, the INSIDER has a solid reputation for timely, exclusive stories. Subscribers tell us they really use the news they read in the INSIDER (which is why we print both addresses and phone numbers of key contacts at the end of articles).

Every week, Jems editors scour hundreds of publications, make dozens of phone calls and read reports from all over the country to get the scoop on legal decisions, new government regulations, late developments and trends in the EMS industry. We take raw facts and data, compare them, and create concise analyses that show what's really happening in EMS.

Wouldn't you like to receive the best inside information - every month-without spending your own precious time compiling it? Now you can.

\section{Subscribe to the EMS INSIDER.}

Get the time-sensitive news you can act on with confidence.

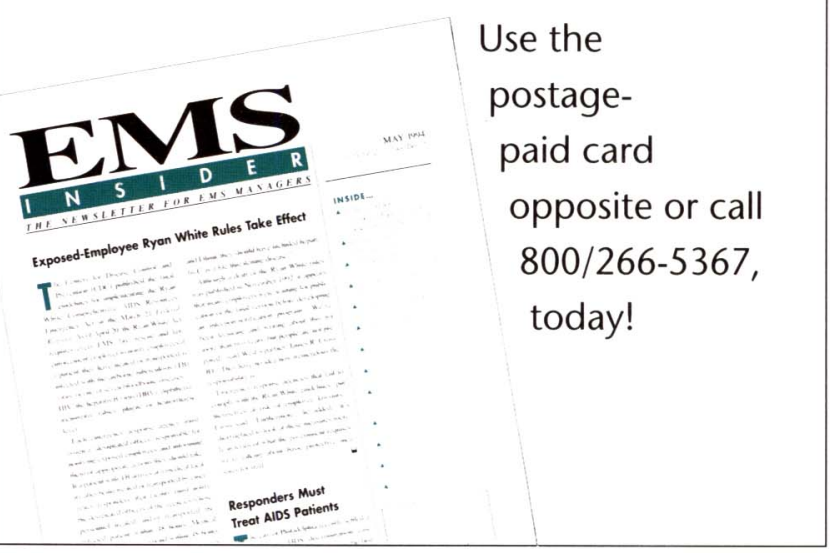

